\title{
Adolescente em conflito com a lei: Representações, motivações e punições
}

\author{
Teenagers in conflict with the law: Representations, motivations and punishments \\ Danielly Bart do Nascimento[a], Anna Beatriz Carnielli Howat-Rodrigues ${ }^{[b]}$, Edinete Maria Rosa ${ }^{[c]}$, Júlio César Pompeu ${ }^{[d]}$
}

\footnotetext{
${ }^{[a]}$ Mestre em Psicologia pela Universidade Federal do Espírito Santo (UFES), Vitória, ES - Brasil, e-mail: danybartnasc@yahoo.com.br

${ }^{[b]}$ Mestre em Psicologia e doutoranda em Psicologia Experimental pela Universidade de São Paulo (USP), São Paulo, SP - Brasil, e-mail: biacarnielli@ yahoo.com.br

${ }^{[c]}$ Doutora em Psicologia Social pela Universidade de São Paulo (USP), professora adjunta da Universidade Federal do Espírito Santo (UFES), Vitória, ES - Brasil, e-mail: edineter@ gmail.com

${ }^{\text {[d] }}$ Mestrado em Direito pela Pontifícia Universidade Católica do Rio de Janeiro (PUC-Rio), professor de Ética e Teoria do Estado, do Departamento de Direito da Universidade Federal do Espírito Santo (UFES), Vitória, ES - Brasil, e-mail: julio@pompeu.org
}

Recebido: 13/02/2011 Received: 02/13/2011

Aprovado: 06/04/2011 Approved: 04/06/2011

\section{Resumo}

Neste estudo, objetivou-se analisar a representação social de adolescente em conflito com a lei entre universitários, bem como a motivação que estes atribuíam para a criminalidade e a punição que julgavam necessária para o autor do ato infracional. Participaram 53 estudantes universitários dos cursos de Psicologia e Direito que responderam a um questionário com perguntas fechadas sobre os próprios dados sociodemográficos e questionário estruturado a partir de uma história dilema contendo ativação contextual com manipulação de variável econômica bairro (rico X pobre) a respeito de um adolescente em questão. A análise de correspondência sugeriu aproximação positiva entre condição financeira e escolaridade. Como motivação para o crime foi apontada, principalmente, a dificuldade financeira dos dois adolescentes e dentre as punições, a prisão foi a forma mais citada pelos dois grupos. As representações sociais se mostraram perpassadas pela baixa condição socioeconômica como sinônimo de criminalidade pautadas, ainda, numa visão punitiva e vingativa.

Palavras-chave: Adolescente em conflito com a lei. Jovem. Teoria das representações sociais.

\section{Abstract}

This study aimed to analyze the social representation of college's students about teenagers in conflict with the law, as well as the motivation that the college students attributed for crime and the punishment they judge necessary to infraction authors. It included 53 Psychology and Law college students, who answered a self-reported questionnaire on sociodemographic data and a questionnaire structured from the point of view of a dilemma story with contextual activation containing handling of neighborhood as an economic variable (poor X rich) of a given teenager. Correspondence analysis suggested positive approach between education and financial condition. As motivations for the crime were mostly pointed financial difficulties of two teenagers and, as punishment, the prison was the most cited way by both groups. The social representations were permeated by low socioeconomic status as a synonym of crime guiding to a punitive and vindictive view.

Keywords: Teenagers in conflict with the law. Youth. Social representation theory. 


\section{Introdução}

Moscovici (1978) define representação social como uma forma de conhecimento particular, formada por meio de um comportamento ativo e autônomo do indivíduo dentro do processo de construção da sociedade, com a finalidade de elaborar os comportamentos e as comunicações entre indivíduos. Para o autor, o indivíduo só existe dentro da rede social (Moscovici, 1985). Desta forma, apenas podemos considerar como representação social o conhecimento que faz parte do cotidiano das pessoas por meio do senso comum com função de compreender, interpretar e agir sobre a realidade (Alexandre, 2004). De acordo com Abric (1998), as representações sociais possuem como função compreender e explicar a realidade social, definir a identidade grupal, proteger a especificidade do grupo, guiar os comportamentos e práticas sociais e justificar tomadas de posição e de comportamentos. A representação social pode ser tomada como um instrumento da Psicologia Social, pois permite compreender a formação do pensamento social na medida em que propicia uma articulação dinâmica entre o social e o psicológico (Alexandre, 2004).

\section{Conceito e representações sociais da adolescência}

0 termo adolescência muitas vezes, é confundido com o termo juventude, pois ora esses termos se sobrepõem, ora referem-se a campos distintos. A adolescência seria uma fase iniciada antes da juventude, mas também participa dela. Já a juventude estaria para além da adolescência e, neste sentido, seria uma faixa etária, um período da vida, um contingente populacional, uma categoria social ou ainda, uma geração (Freitas, 2005).

Grossman e Cardoso (1997), ao analisarem documentos oficiais da Organização Mundial de Saúde (OMS), Organização Panamericana de Saúde (OPAS) e Ministério da Saúde, identificaram três critérios que podem ser usados para a definição de adolescência: (1) o biopsicosocial, que considera o desenvolvimento psicológico e o social vinculado ao biológico que se refere às transformações físicas da puberdade, (2) o cronológico, definido das necessidades das relações sociais cotidianas e de intervenções de natureza educacional, psicológica, médica e legal entre outras e (3) o padrão típico de adolescente, em que não se admite que a adolescência seja um período vivido de forma homogênea por todos, ou seja, é um período com características próprias. Nesta análise, os autores concluíram que a adolescência estaria compreendida entre 10 e 19 anos, sendo a primeira fase entre 10 e 14 anos e a segunda entre 15 e 19 anos, enquanto a juventude seria o período compreendido entre os 15 e 24 anos.

Neste artigo, consideraremos a adolescência como um processo biopsicossocial e, de acordo com Ozella (2002), como sendo um construto histórico a partir de fatos sociais e psicológicos embasados pela significação conferida pela cultura e linguagem que perpassa as relações sociais. Levaremos em conta ainda, que a adolescência não seria um período natural, e sim um momento carregado de significado e interpretação humana e sua constituição envolve as necessidades sociais, econômicas e das características estabelecidas no processo (Sousa \& Brandão, 2008). Conforme a Lei n. 8.069 de 1990 (Brasil, 1990), Estatuto da Criança e do Adolescente (ECA), a adolescência é definida como sendo o período entre 12 e 18 anos de idade.

0 uso do termo adolescência, em nosso país, ganhou especial destaque na década de 1980 quando os movimentos sociais em defesa dos direitos da infância e adolescência chamaram a atenção para essa fase que possui características peculiares de desenvolvimento e exige cuidados e proteção (Freitas, 2005).

No Brasil, são frequentes as notícias relacionadas à juventude como problema social, principalmente em relação à violência (Abramo, 1997). A imprensa costuma veicular um perfil de jovem violento e criminoso, pronto para praticar qualquer tipo de infração e até mesmo matar sem motivo aparente. A imagem do jovem veiculada pela mídia cotidiana revela uma opinião de que este seja emocionalmente carente, irresponsável, libertino, permissivo sexualmente, negligente e imaturo, além de vulnerável às más influências do meio (Adorno, Bordini \& Lima, 1999). Essa imagem negativa pode estar relacionada ao crescente aparecimento de crianças em situação de rua desde a década de 1970 nas grandes cidades e a crescente violência urbana. Trata-se de uma relação estabelecida pela opinião pública de que jovens de camadas sociais empobrecidas estariam diretamente ligados a crimes urbanos, principalmente crimes relacionados ao tráfico de drogas (Adorno, Bordini \& Lima, 1999), sendo este e outros crimes atribuídos, na maioria das vezes, aos adolescentes do sexo masculino (Espíndula et al., 2006). 
Uma pesquisa realizada por Andrade (2005), a partir da análise de 449 unidades de informação extraída do jornal Folha de São Paulo, entre os anos de 1980 e 2001, mostrou que meninos de rua por si só não ganham as páginas de jornal com destaque, a menos que estejam associados à violência. Frequentemente as matérias referem-se a essas crianças como exército paralelo, quadrilha, drogados, entre outros adjetivos como pivete e trombadinha. As matérias enfatizam que eles praticam e sofrem roubos, arrastões, tráfico, assassinatos, abusos sexuais, violência policial, entre outros tipos de violência. Essas crianças são rotuladas e estigmatizadas como uma categoria negativa, estendendo-se para grupos de crianças e adolescente pobres, mesmo que não estejam em situação de rua (Rosemberg \& Andrade, 2007).

$\mathrm{Na}$ pesquisa realizada por Espíndula et al. (2006), em que foram analisadas notícias jornalísticas para a obtenção de uma representação social do adolescente em conflito com a lei, 83\% das notícias referentes aos adolescentes publicadas entre agosto de 2003 e setembro de 2004 foram encontradas no caderno de polícia e segurança. A pesquisa mostra que o crime contra o patrimônio público apresenta maior percentual de ocorrência $(32,41 \%)$ dentre aqueles divulgados pelos meios jornalísticos analisados. Além disso, a forma com que crimes com maior potencial ofensivo, como assassinatos, são narrados contribui para a formação de uma imagem de criminoso incorrigível para o adolescente em conflito com a lei, mesmo sendo estes divulgados em menor número $(22,13 \%)$.

Também na pesquisa realizada por Espíndula et al. (2006) encontramos depoimentos de pessoas que acreditam que adolescentes em conflito com a lei precisam de punições severas, tais como a diminuição da maioridade penal para 16 anos e o aumento no tempo de internação (que hoje é de, no máximo, três anos). É importante ressaltar como ainda na atualidade, mesmo após anos de existência do ECA, os adolescentes ainda são alvo de antigas concepções ancoradas nos preceitos do antigo Código de Menores que os desqualificam ao denominá-los como: menor, infrator ou, adolescentes infratores.

O ECA, instrumento de proteção em favor de crianças e adolescentes, é visto por uma parcela social como um instrumento de defesa para jovens delinquentes que não recebem uma punição equivalente à gravidade dos atos infracionais que praticam. Estes insistem em considerar as medidas socioeducativas dispostas na lei muito brandas e acreditam que punições mais severas teriam resultados mais eficazes (Adorno, Bordini \& Lima, 1999).

Por outro lado, Menandro, Trindade e Almeida (2005) realizaram um trabalho sobre a percepção do adolescente/jovem a partir da análise de notícias e comentários disponíveis na revista Veja em dois períodos, entre 1968 a 1974 e entre 1996 a 2002 e encontraram uma percepção, referente ao segundo período, de adolescente em desenvolvimento que precisa de proteção, sendo a família o núcleo responsável por sua educação. A possibilidade de envolvimento com drogas lícitas e ilícitas diante da vulnerabilidade causada, por exemplo, pela confusão de sentimentos de insegurança e ansiedade, sobretudo sob circunstâncias pessoais e sociais também é considerada. Ao jovem também é atribuída a fase de decisão sobre qual carreira profissional será seguida, e ainda são vistos como atores da cultura de consumo.

Encontra-se ainda na jurisdição brasileira o jovem vítima de violência e organismos tanto governamentais quanto não governamentais empenhados na proteção de crianças e adolescentes principalmente por meio de políticas públicas em reconhecimento ao risco social a que podem estar expostos. É na perspectiva da proteção e da socioeducação que o ECA estabelece medidas aplicáveis aos adolescentes autores de ato infracional reconhecendo o caráter peculiar de desenvolvimento em que se encontram esses sujeitos. É verdade que nem sempre o que prescreve a Lei é cumprido pelo Estado e pela sociedade civil, e podemos encontrar ainda hoje formas discriminatórias de tratamento e de intervenção com a população sem que isso repercuta negativamente na opinião pública. Contudo é bastante recente o estudo sobre o crescimento da requentes a juvenil e a eficácia do sistema de justiça e do poder público no combate à mesma (Adorno, Bordini \& Lima, 1999). Estudos estão cada vez mais frequentes, o que demonstra o crescente interesse acadêmico pelo tema.

\section{0 adolescente em conflito com a lei e sua responsabilização penal}

São considerados adolescentes em conflito com a lei aqueles que na data do fato possuíam entre 12 e 18 anos e cometeram um ato infracional ou conduta descrita como crime ou contravenção penal. São assegurados aos adolescentes os processos legais com a garantia de pleno e formal conhecimento da 
atribuição de ato infracional, igualdade na relação processual, defesa técnica por advogado, assistência judiciária gratuita e integral aos necessitados, direito de ser ouvido pessoalmente pela autoridade competente e direito de solicitar a presença dos pais ou responsáveis em qualquer fase do procedimento (Brasil, 1990).

Entre as medidas socioeducativas aplicadas em adolescentes em conflito com a lei estão a advertência, a obrigação de reparar o dano, a prestação de serviço à comunidade, a liberdade assistida, a inserção em regime de semiliberdade ou a privação de liberdade em caso de flagrante ou ordem escrita pela autoridade judiciária competente. A medida aplicada ao adolescente levará em conta a capacidade do mesmo de cumpri-la e também as circunstâncias e a gravidade do ato infracional, sendo o trabalho forçado inadmissível. Os adolescentes portadores de doença ou deficiência receberão tratamento individual e especial condizentes às suas condições (Brasil, 1990).

Após a decisão da autoridade judiciária competente em relação à medida socieducativa a ser cumprida pelo adolescente, há de se observar algumas garantias para o seu cumprimento. Em caso de Prestação de Serviço à Comunidade, a atividade não deverá prejudicar a frequência escolar; na Liberdade Assistida, deverá garantir-se a frequência escolar e orientá-lo à profissionalização e ao mercado de trabalho; no Regime de Semiliberdade, a escolarização e a profissionalização são obrigatórias e no caso de Internação também são obrigatórias às atividades pedagógicas (escolarização e profissionalização), além de ser tratado com respeito e dignidade; permanecer internado na mesma localidade ou naquela mais próxima ao domicílio de seus pais ou responsáveis; receber visitas semanalmente; corresponder-se com seus familiares e amigos; ter acesso a objetos de higiene e asseio pessoal; habitar alojamento em condições adequadas de higiene e salubridade entre outras, inclusive em relação a obter informações sobre o seu processo (Brasil, 1990).

Os motivos para que um adolescente cometa um ato infracional ainda são considerados complexos e de difícil descrição, mas muitos autores concordam que esses adolescentes de alguma forma estão buscando reconhecimento, pertencimento ou obtenção de algo que lhes falta (Castro, 2002). Há ainda outros fatores de risco para que adolescentes cometam atos infracionais, como: relações familiares conflituosas, influência dos amigos (Assis, 1999; Brank, Lane, Turner, Fain \& Sehgal, 2007) drogas, determinados tipos de lazer, autoestima deteriorada, posição entre irmãos (relacionada à ordem de nascimento), princípios éticos e presença de vínculos afetivos relacionados à escola (Assis, 1999).

No Brasil, a maioria dos adolescentes em situação de internação em estabelecimento educacional é composta por excluídos sociais. Embora a situação de miséria, a falta de bens materiais e de perspectivas não seja suficiente para afirmarmos a causa dos atos infracionais, esses fatores constituem uma condição de vulnerabilidade (Castro, 2002).

Sendo assim, considerando a Teoria das Representações Sociais, este trabalho tem por interesse investigar as Representações Sociais sobre adolescentes em conflito com a lei entre universitários dos cursos de Psicologia e Direito de uma universidade pública, bem como a motivação que atribuíam para a criminalidade e as punições cabíveis ao autor do ato infracional.

\section{Metodologia}

\section{Participantes}

Participaram desta pesquisa, de forma voluntária, 53 estudantes universitários dos cursos de Direito e Psicologia de uma universidade pública no Estado do Espírito Santo.

\section{Instrumento}

Foi utilizado um questionário com perguntas fechadas sobre o perfil do participante (sexo, idade, curso, período e renda familiar). Como ativação contextual, uma história sobre o personagem João foi contada com a mudança da variável bairro. Nesta história, João era um adolescente de 16 anos, morador de bairro pobre ou rico do município de Vitória, ES, órfão de pai, que, ao passar por dificuldades financeiras foi convidado por um amigo(a) a participar de uma atividade ilícita. Ao participante perguntou-se, a partir de perguntas fechadas e abertas, sobre: características do amigo(a) (sexo, idade, onde mora, escolaridade, se trabalha - qual a profissão), a atividade ilícita em questão, se o adolescente aceitaria a proposta e qual a punição que o adolescente mereceria considerando que ele tenha aceito a proposta e tenha sido pego pela polícia. 


\section{Procedimentos de coleta e análise de dados}

A coleta de dados foi realizada de forma coletiva em turmas dos cursos de Direito e de Psicologia, após permissão do professor responsável pela turma no momento da aplicação e a ciência dos objetivos da pesquisa e consentimento dos participantes.

As questões abertas passaram por uma técnica da análise de conteúdo, a análise categorial em que o texto é dividido em unidades, em categorias semelhantes (Bardin, 1977/2004). O programa (SPSS) Statistical Package for the Social Sciences versão 13.0 foi utilizado para realizar as análises estatísticas. Cálculos de estatística descritiva e frequencial foram realizados para a análise do perfil dos participantes e para as questões sobre perfil do amigo de João e pena merecida. Utilizou-se o teste Qui-quadrado a fim de examinar a associação entre o tipo de história (menino pobre X menino rico) e o curso dos participantes e as categorias: onde o amigo mora, escolaridade do amigo, se o amigo trabalha, profissão do amigo, a prática ilícita proposta pelo amigo, a decisão de João de aceitar ou não a proposta do amigo e o tipo de pena que João mereceria, caso tivesse aceito a proposta. Finalmente, analisaram-se as relações entre as características do amigo de João (local de moradia, escolaridade) em uma análise de correspondência que é uma técnica de representação gráfica em projeção plana das relações multidimensionais das distâncias do Qui-quadrado entre as categorias das variáveis estudadas (Batista, Escuder \& Pereira, 2004).

\section{Resultados}

\section{Perfil dos participantes}

Participaram deste estudo 53 estudantes universitários, os quais 32 eram do sexo feminino e 21 do sexo masculino dos cursos de Psicologia $(43,4 \%)$ e de Direito (56,6\%) com idade média de 21,47 anos. Em relação à etnia dos participantes, a maioria dos entrevistados declarou-se branco $(60,4 \%)$, os demais declararam-se pardos $(30,2 \%)$ e negros $(3,8 \%)$. E quanto à renda mensal familiar, $54,7 \%$ declarou ter renda maior ou igual a $\mathrm{R} \$ 3.761,00$, $28,3 \%$ entre $\mathrm{R} \$ 1.881,00$ a $\mathrm{R} \$ 3.760,00$ e $17 \%$ inferior a $\mathrm{R} \$ 1.880,00$.

\section{Perfil do amigo de João, motivações e punições para o crime}

Os participantes atribuíram uma idade média de 19,41 anos para o amigo de João, portanto, alguém maior de idade. A partir do teste do Qui-quadrado, evidenciaram-se diferenças estatisticamente significativas entre o tipo de história e o local de moradia $\left(\chi_{(3)}^{2}=26.009, \mathrm{p}\right.$ $=0.0001)$ e a escolaridade $\left(\chi_{(5)}^{2}=16.370, \mathrm{p}=0.006\right)$ do amigo de João. Quando o personagem era pobre, os participantes tenderam a responder com maior frequência que o amigo morava em bairros pobres $(85,2 \%)$ e tinha escolaridade de ensino fundamental incompleto (52\%), enquanto, para o personagem que morava em bairro rico, as respostas tenderam para um perfil de amigo que também morava em bairro rico (56\%) e com escolaridade de ensino médio completo (46,2\%).

A análise de correspondência entre o tipo de história, o local de moradia e a escolaridade do amigo de João, evidenciou (Figura 1) duas dimensões para a projeção plana das categorias das variáveis que juntas representaram 98,5\% das variações das distâncias do Qui-quadrado. Sugere-se, portanto, aproximação entre história do menino rico, moradia do amigo em bairro rico e escolaridade do amigo de ensino médio completo e ensino superior e história do menino pobre, moradia do amigo em bairro pobre e escolaridade do amigo de ensino fundamental e médio incompletos.

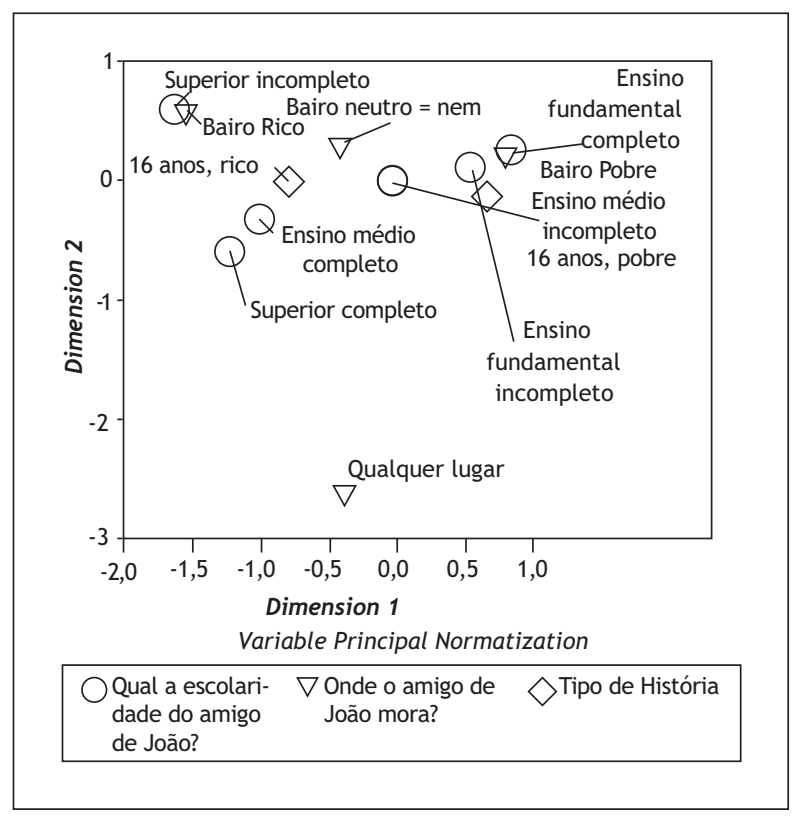

Figura 1 - Mapa das relações entre categorias de tipo de história, local de moradia e escolaridade do amigo de João

Fonte: Dados da pesquisa. 
Em relação às respostas analisadas, em termos dos cursos dos participantes, houve diferença estatisticamente significativa para a categoria $o$ amigo trabalha $\left(\chi_{(1)}^{2}=6.031, \mathrm{p}=0.014\right)$ e para o tipo de penalidade que João mereceria se aceitasse a proposta do amigo $\left(\chi_{(4)}^{2}=12.531, p=0.014\right)$. Sessenta e cinco vírgula dois por cento dos estudantes de Psicologia consideraram que o amigo de João trabalhava enquanto, $31 \%$ dos estudantes de Direito assim o fizeram. Trinta e oito e meio por cento dos que responderam a história do menino pobre e $53,8 \%$ dos que responderam a história do menino rico acharam que o amigo de João trabalhava, dentre estes, $23,8 \%$ consideraram o tráfico de drogas e $19 \%$ atividades ilícitas como profissão.

Em relação à prática ilícita, os participantes que responderam ao questionário do adolescente morador de bairro pobre disseram que João foi convidado a participar do tráfico de drogas $(92,6 \%)$ e da atividade de contrabando $(3,7 \%)$, sendo que um participante não respondeu, representando $3,7 \%$ das respostas. Os participantes que responderam o questionário do adolescente morador de bairro de classe média alta disseram que João foi convidado a participar da prática de tráfico de drogas $(75 \%)$, de contrabando $(7,0 \%)$, da prática de prostituição $(3,6 \%)$, desvio de dinheiro $(3,6 \%)$, prática de funcionário fantasma $(3,6 \%)$, pirataria $(3,6 \%)$ e assalto $(3,6 \%)$.

Dentre os participantes, $80 \%$ dos que avaliaram a história do menino pobre e $65 \%$ dos que avaliaram a história do menino rico acharam que ele aceitaria a proposta. Tanto estudantes de Direito $(42,9 \%)$ quanto estudantes de Psicologia $(46,7 \%)$ propuseram a medida socioeducativa e/ou medida protetiva como pena ou como uma forma de amparo para João. Os estudantes de Direito ainda tiveram alta frequência de respostas $(42,9 \%)$ assinalando que a penalidade merecida era aquela prevista em lei, enquanto os estudantes de Psicologia ainda consideraram a detenção (40\%) como possível penalidade para João.

Entre os motivos para o João que mora em bairro de classe média ter aceitado a proposta encontramos como justificativa a dificuldade financeira $(31,9 \%)$, a influência do amigo $(22,7 \%)$, a fragilidade emocional $(22,7 \%)$, a imaturidade $(9,1 \%)$, a ausência de valores morais $(9,1 \%)$ e a certeza de impunidade $(4,5 \%)$. Entre os motivos para ele não aceitar estavam, presença de valores morais $(55,6 \%)$, morar em bairro de classe média alta
$(22,2 \%)$, trabalhar em atividade lícita $(11,11 \%)$ e medo da punição $(11,11 \%)$.

Entre os motivos para João, morador de bairro pobre, aceitar a proposta estava dificuldade financeira $(44,1 \%)$, falta de oportunidade $(23,5 \%)$, viver em bairro pobre, $(8,8 \%)$, ausência do pai $(8,8 \%)$, dinheiro fácil (5,9\%), influência do amigo $(5,9 \%)$ e ausência de valores morais (3,0\%). Entre os motivos para ele não aceitar estavam presença de valores morais (50\%), medo da punição $(33,3 \%)$ e trabalhar em atividade lícita $(16,7 \%)$.

\section{Discussão}

Em relação aos dados coletados a respeito das características do amigo do adolescente, podemos constatar que, nessa amostra de participantes, se confirma a tese de que o perfil de delinquência seria do adolescente/jovem, visto que os participantes definiram o amigo do adolescente com idade média de 19,41 anos. Como 85,2\% dos participantes consideraram o amigo de João além de jovem, também um morador de periferia, podemos constatar que o jovem de classe baixa estaria dentro de uma categoria negativa, a quem se atribui todo tipo de conduta irregular possível, como no estudo de Rosemberg e Andrade (2007). Podemos somar a isso uma representação de pessoa com pouca instrução (baixa escolaridade), que não possui trabalho e por isso sem perspectiva, já que $52 \%$ disseram que o amigo teria apenas o ensino fundamental incompleto. Além dessas características, os participantes acreditam que o amigo é do sexo masculino, demonstrando um imaginário de jovem, do sexo masculino, morador de periferia, desocupado, delinquente, violento e ameaçador.

A consideração do tráfico de drogas e das atividades ilícitas como profissões revela a possibilidade das pessoas começarem a considerar tais práticas como ocupações tão comuns que podem ser consideradas um trabalho. Essa visão deve nos chamar a atenção para como estamos lidando com o fenômeno do tráfico e outras atividades irregulares, como estamos aceitando, ou como estão nos impondo sua expansão a ponto de banalizarmos e as legitimarmos como atividades tão possíveis quanto um trabalho honesto.

Em relação à prática ilícita que o adolescente foi convidado a participar, o tráfico de drogas é o mais apontado pelos participantes que responderam aos 
dois tipos de questionários. Essa postura confirma que para a maioria das pessoas, a possibilidade de envolvimento do adolescente/jovem com drogas, seja o consumo ou o tráfico é algo muito presente, como aponta os estudos de Menandro, Trindade e Almeida (2005), Adorno, Bordini e Lima (1999) e Rosemberg e Andrade (2007).

Chama a atenção o fato de terem sido apontadas várias atividades ilícitas para o adolescente morador do bairro rico, enquanto para o morador de bairro pobre foram admitidas apenas duas possibilidades (tráfico e contrabando). Isso pode ser explicado pelo perfil dos participantes da pesquisa: estudantes universitários - o que já aponta relevante grau de inclusão social - sendo $83 \%$ com renda superior a R\$1.880,00. Esse perfil socioeconômico, característico da classe média, permite inferir que, ao analisar as possíveis condutas criminosas de João, a proximidade social havida entre os participantes e o personagem de classe média exerceu influência. Pesquisas em psicologia cognitiva (Quattrone \& Jones, 1980; Linville, Fisher \& Salovey, 1989; Kashima \& Kashima, 1993) apontam para o fato de, ao julgarmos, quanto maior a distância social ou menos interações sociais tivermos com indivíduos pertencentes a grupos estranhos ao nosso, maior a tendência a julgar a partir de um modelo ou estereótipo sem considerar eventuais singularidades das pessoas avaliadas. Ao contrário, quanto maior a proximidade social ou o número de experiências ou contatos reais com indivíduos do grupo estigmatizado, mais singularidades o estereótipo dos indivíduos do grupo comporta. Em suma, quanto mais próximos, mais diferentes uns dos outros.

A maior parte dos participantes acredita que, diante das circunstâncias, os adolescentes dos dois bairros aceitam a proposta do amigo. Julgam que a dificuldade financeira, a influência do amigo e a ausência de valores morais seriam motivos comuns aos dois adolescentes para o ingresso na vida do crime, sendo a dificuldade financeira o motivo mais forte. Contudo, os participantes que responderam ao questionário do adolescente morador de bairro rico admitem outros fatores de risco como fragilidade emocional, imaturidade e certeza de impunidade para entrada do adolescente no mundo do crime. Enquanto isso, o adolescente de bairro pobre possui como fatores de risco a falta de oportunidade, viver em bairro pobre, ausência do pai e a possibilidade de dinheiro fácil.
Essa diferença encontrada entre fatores de risco para adolescente de bairro rico e fatores de risco para adolescente de bairro pobre demonstra duas representações diferentes de adolescência na qual se admite um adolescente de bairro rico próximo ao encontrado na pesquisa de Menandro, Trindade e Almeida (2005) na qual a confusão de sentimentos, a insegurança e a ansiedade sob circunstâncias pessoais e sociais são consideradas como fatores que podem deixar o adolescente vulnerável ao crime, enquanto que o adolescente de bairro pobre diante da ausência do pai, da falta de oportunidade e a possibilidade de conseguir dinheiro facilmente é percebido como um perigo latente. Somamos a isso, a justificativa de que para os participantes o fato de o adolescente morar em bairro pobre pode facilitar seu envolvimento com o crime, enquanto que entre os motivos para o adolescente de bairro rico não entrar no crime é justamente viver em um bairro de classe média alta.

Dentre as punições atribuídas ao adolescente, podemos dizer que boa parte dos participantes, $(42,9 \%)$ estudantes de Direito e $(46,7 \%)$ estudantes de Psicologia, possuem o conhecimento de que adolescentes em conflito com a lei possuem seus direitos e devem ser tratados com medidas socioeducativas e medidas protetivas. Reconhecem que possuem direito a um tratamento diferenciado ao de pessoas maiores de idade em conflito com a que cometeram crime. Porém, é lamentável que ainda haja aqueles que acreditam que adolescentes autores de ato infracional são criminosos incorrigíveis e devem amargar punições severas como, por exemplo, a prisão.

Atos de julgamento - e a indicação da pena ideal não deixa de ser um deles - são invariavelmente atos identitários, pois todo julgamento é um juízo realizado por um sujeito A - que se identifica de determinada maneira - com relação a um sujeito B - que é representado de um modo particular pelo sujeito $\mathrm{A}$. Neste sentido, Abric (1994, p. 16) aponta que, dentre as funções das representações sociais, estariam a identitária, que define a identidade e salvaguarda a identidade do grupo e a justificadora, que permitiria justificar a posteriori o comportamento e tomadas de posição de elementos do grupo, sendo estas e outras funções das representações sociais, apesar de distinguíveis em termos conceituais, complementares com relação ao modo de funcionamento das representações. 
A existência de representações sociais distintas de adolescentes em conflito com a lei implica, portanto, em critérios distintos quanto à justa retribuição pelo delito eventualmente cometido. Da mesma maneira que a proximidade social afeta o modo de representar os possíveis delitos de João rico e pobre, ela também pode afetar o princípio de justiça que orienta o julgamento. A lei, tida como critério formal de julgamento, parte do pressuposto de que o tratamento justo deveria levar em conta apenas as condutas praticadas pelos sujeitos em julgamento, independentemente de sua condição social. Permitir variações no modo de julgar seria injusto. Porém, uma vez que os adolescentes em conflito com a lei são representados de formas distintas, o princípio da igualdade de todos perante a lei é posto em cheque.

A proximidade social entre julgadores e julgados pode acionar critérios mais flexíveis de julgamento, da mesma maneira que ocorre quando os sujeitos da pesquisa apontam os possíveis delitos cometidos por João. Em sentido contrário, quanto maior a distância social, menos flexíveis os critérios de julgamento e, portanto, de apenação. Em suma, quanto maior a proximidade social entre julgadores e julgados, mais o princípio de justiça exigiria que fossem levadas em conta circunstâncias individualizantes que explicassem o comportamento daquele indivíduo em particular. Por outro lado, quanto maior a distância social que os separa, menos exigentes os critérios e mais o indivíduo é julgado independentemente de suas singularidades. Aplicado tal critério à pesquisa, temos que a prisão, pena pouco flexível e mais violenta, é tida como mais adequada para os mais socialmente distantes dos sujeitos da pesquisa, ao passo que as medidas socioeducativas, mais flexíveis e brandas, podem ser vistas como mais adequadas e justas.

\section{Considerações finais}

Esta pesquisa traz a representação social do adolescente em conflito com a lei a partir de dados coletados de uma amostra de participantes universitários de Psicologia e Direito. Por meio dos resultados, podemos observar que a representação dos participantes, a respeito do adolescente autor de ato infracional, está ancorada na baixa condição socioeconômica (pobreza) e objetivada no sujeito de sexo masculino envolvido com o tráfico de drogas.
O que chama a atenção aqui não é somente o conteúdo da representação, já que esta é tão difundida pela imprensa e perpassa o imaginário comum da sociedade, e chama-nos a atenção a quem pertence tal representação. Os universitários em questão fazem parte de um grupo de futuros profissionais que poderão trabalhar diretamente na atenção aos adolescentes em conflito com a lei, no entanto ainda guardam uma percepção negativa e estereotipada de um adolescente que, por causa da sua condição de vida na periferia, com baixa escolaridade, pertencente a uma família desfeita e terá grande possibilidade de ingressar na vida do crime.

Outro resultado importante nos dados coletados é o conhecimento demonstrado pela amostra de participantes a respeito da lei de proteção à infância e adolescência. Contudo é possível perceber que isso não é suficiente para que proponham medidas alternativas, pois grande parte propõe a internação como sanção ao adolescente. Tal pensamento traz um indicativo de que esses futuros profissionais, ao invés de primarem pelo convívio familiar e comunitário desses adolescentes, compartilham a ideia de que precisam ser mantidos afastados do convívio social.

Nesse sentido, precisamos pensar na qualidade da atenção, dispensada a esses adolescentes. Tal atenção deve seguir o cumprimento dos artigos dispostos no Estatuto, pois sabemos que a implementação da lei, na sua forma correta, depende de como estão orientadas as práticas dos profissionais e que tais práticas são influenciadas pelas representações que possuem.

\section{Referências}

Abramo, H. W. (1997). Considerações sobre a tematização social da juventude no Brasil. In A. Peralva \& M. Sposito (Org.). Juventude e contemporaneidade. Revista Brasileira de Educação, 5(6), p. 25- 36.

Abric, J.-C. (1994). Les représentations sociales: Aspects théoriques. In J.-C. Abric (Org.). Pratiques sociales et représentations (pp. 14-15). Paris: Presses Universitaires de France.

Abric, J.-C. (1998). A abordagem estrutural das representações sociais. In A. S. P. Moreira \& D. C. Oliveira (Org.). Estudos interdisciplinares de representação social (pp. 27-38). Goiânia: AB. 
Adorno, S., Bordini, E. B., \& Lima, R. S. (1999). O adolescente e as mudanças na criminalidade urbana. São Paulo em Perspectiva, 13(4), 62-74.

Alexandre, M. (2004). Representação social: Uma genealogia do conceito. COMUM, 10(23), 122-138.

Andrade, M. P. de. (2005). A Categoria "meninos de rua" na mídia: Uma interpretação ideológica. São Paulo: Tese de Doutorado em Psicologia Social, Pontifícia Universidade Católica de São Paulo, São Paulo.

Assis, S. G. (1999). Traçando caminhos em uma sociedade violenta: A vida de jovens infratores e de seus irmãos não infratores. Rio de Janeiro: FIOCRUZ.

Bardin, L. (2004). Análise de conteúdo. Lisboa: Edições 70. (Publicado originalmente em 1977).

Batista, L. E., Escuder, M. M. L., \& Pereira, J. C. R. (2004). A cor da morte: Causas de óbito segundo características de raça no Estado de São Paulo, 1999 a 2001. Revista de Saúde Pública, 38(5), 630-636.

Brank, E., Lane, J., Turner, S., Fain, T., \& Sehgal, A. (2008). An experimental juvenile probation program: Effects on parent and peer relationships. Crime \& Delinquency, 54(2), 193-224.

Brasil. Lei n. 8.069, de 13 de julho de 1990. Dispõe sobre o Estatuto da Criança e do Adolescente, e dá outras providências. Diário Oficial [da] República Federativa do Brasil, Poder Legislativo, Brasília, DF, 16 jul. 1990. p. 13563. Recuperado em 23 jul. 2003, em: http://www6.senado.gov.br/legislacao/ ListaTextoIntegral.action?id=75648

Castro, A. L. S. (2002). Os adolescentes em conflito com a lei. In M. L. J. Contini, S. H. Koller \& M. N. S. Barros (Org.). Adolescência e psicologia: Concepções, práticas e reflexões críticas (pp. 122-129). Rio de Janeiro: Conselho Federal de Psicologia.

Espíndula, D. H. P., Aranzedo, A. C., Trindade, Z. A., Menandro, M. C. S., Milena, B., \& Rölke, R. K. (2006). “Perigoso e violento": Representações sociais de adolescentes em conflito com a lei em material jornalístico. PSIC - Revista de Psicologia de Vetor Editora, 7(2), 11-20.

Freitas, M. V. (2005). Juventude e adolescência no Brasil: Referências conceituais. São Paulo: Ação Educativa.
Grossman, E., \& Cardoso, M. H. C. (1997). As bases conceituais dos documentos oficiais de atenção à saúde do adolescente. Revista Brasileira de Crescimento e Desenvolvimento Humano, 7(2), 1-11.

Kashima, E. S., \& Kashima, Y. (1993). Perceptions of general variability of social groups. Social Cognition, 11(1), 1-21.

Linville, P. W., Fisher, G. W., \& Salovey, P. (1989). Perceived distributions of the characteristics of in-group and out-group members: Empirical evidence and a computer simulation. Journal of Personality and Social Psychology, 57, 165-188.

Menandro, M. C. S., Trindade, Z. A., \& Almeida, A. M. O. (2005). Representações sociais da adolescência/juventude a partir de textos jornalísticos (1968/1974 e 1996/2002). Arquivos Brasileiros de Psicologia, 55(1/2), 45-60.

Moscovici, S. (1978). A representação social da psicanálise. Rio de Janeiro: J. Zahar.

Moscovici, S. (1985). Introduccion a el campo de la psicologia. In S. Moscovici (Ed.). Psicologia social: Influencia y cambios de actitudes, individuos y grupos. Barcelona: Paidós.

Ozella, S. (2002). Adolescência: Uma perspectiva crítica. In M. L. J. Conúni, S. H. Koller \& M. N. S. Barros (Org.). Adolescência e psicologia: Concepções, práticas e reflexões críticas (pp. 16-24). Brasília: Conselho Federal de Psicologia.

Quattrone, G. A., \& Jones, E. E. (1980). The perception of variability within in-groups and out-groups: Implications for the law of small numbers. Journal of Personality and Social Psychology, 38(1), 141-152.

Rosemberg, F., \& Andrade, M. P. de. (2007). Infância na mídia brasileira e ideologia. In A. M. Jacó-Vilela \& L. Sato (Org.). Diálogos em psicologia social (pp. 257274). Porto Alegre: Evangraf.

Sousa, A. C. G., \& Brandão, S. N. (2008). Como é ser adolescente do sexo feminino na periferia? Psicologia Ciência e Profissão, 28(1), 82-97. 